guar se a lesăo năo impede de retomar o trabalho e se de volta a trabalho póde resultar aggravação para o mall restante ou prejuizo outro qualquer para a saúde ou pala a vilda do paciente.

E' a doutrina que nos parece mais racional e a que temos semr pre obedecido nos nossos exames.

Dada essa expllicação, justificativa indispensavel para bom entendimento da nossa resposta, ipassemos ao exame do caso.

As fracturas que soffreu o paciente estão consolidadas. Mas ainda não desappareceram as alterações locaes que ldellas resultaram. Entretanto, elle póde voltar ao trabalho sem prejuizo para a sua saúde local ou gerall, como de facto já volitou, embora não possa exercel-o como dantes, com o mesmo vigor, com a mesma efficacia; o paciente. pois, não ficou ao nosso ver inhabilitado para o serviço activo por mais de 30 dias.

\title{
V
}

De accordo com as ligeiras considerações acima feitas, respondemos aos quesitos propostos da maneira seguinte:

Ao $1 .^{\circ}$ : Não.

Ao 2. : Não.

Ao $3 .^{\circ}$ : Não.

Ao 4. : Bom.

FACUldade de MEdicina e cirurgia de São PaUlo

Serviço clinico do Professor Ovidio Pires de Campos, no Hospital Central

da Santa Casa de Misericordia de São Paulo

\section{SYNDROMO ALTERNO DE JACKSON}

COMPIICADO

\author{
Observação do Dr. \\ FRANKLIN DE MOURA CAMPOS
}

A 5 de junho do corrente anno internou-se na 3. E. M. H. da Santa Casa de Misericordia, indo occupar o leito n. 20 , um doente portador de uma hemiplegia direita, associada a multiplas lesões nervosas.

Achamos curioso o caso e resolvemos observal-o. Eis a razão deste trabalho.

Segue a observação:

J. O., brasileiro, preto, solteiro, trabalhador e procedente de Tatuhy. A 2 de junho entrou para 1." E. C. H., sendo 3 dias depois removido á 3." E. M. H. - serviço do Prof. Ovidio Pires de Campos. 


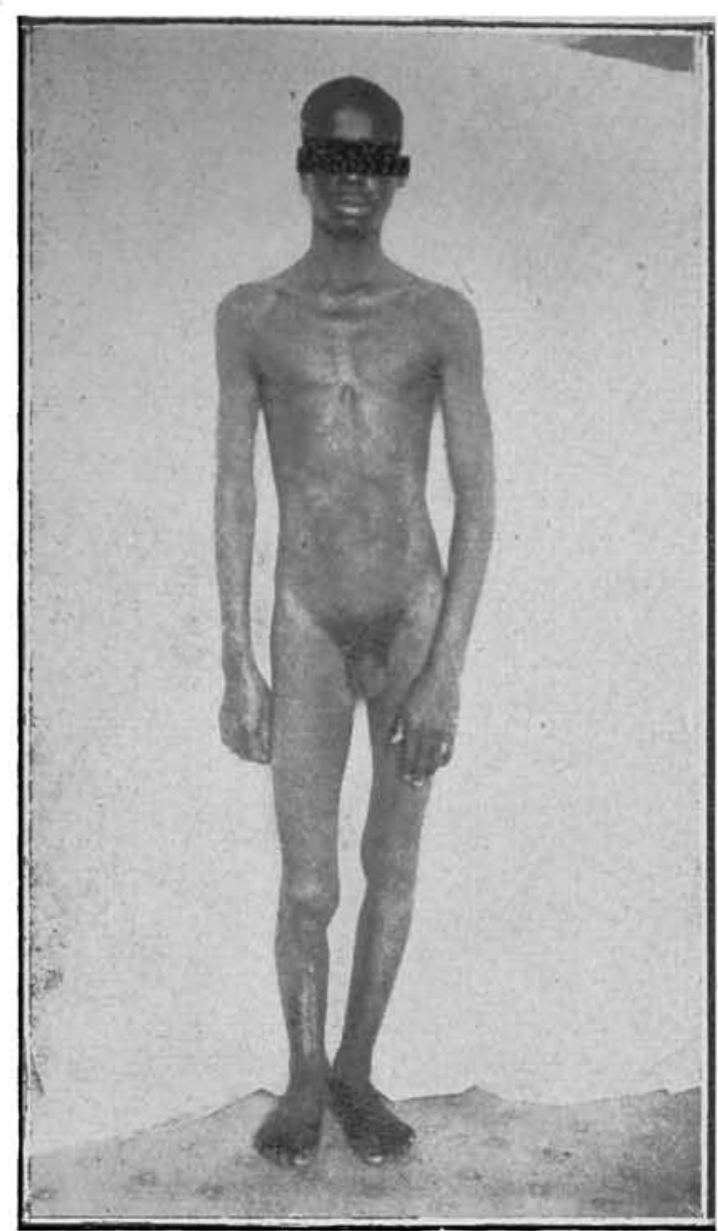

Photographia n.o 1: - Hemiparesia direita. (20-VI-1923).

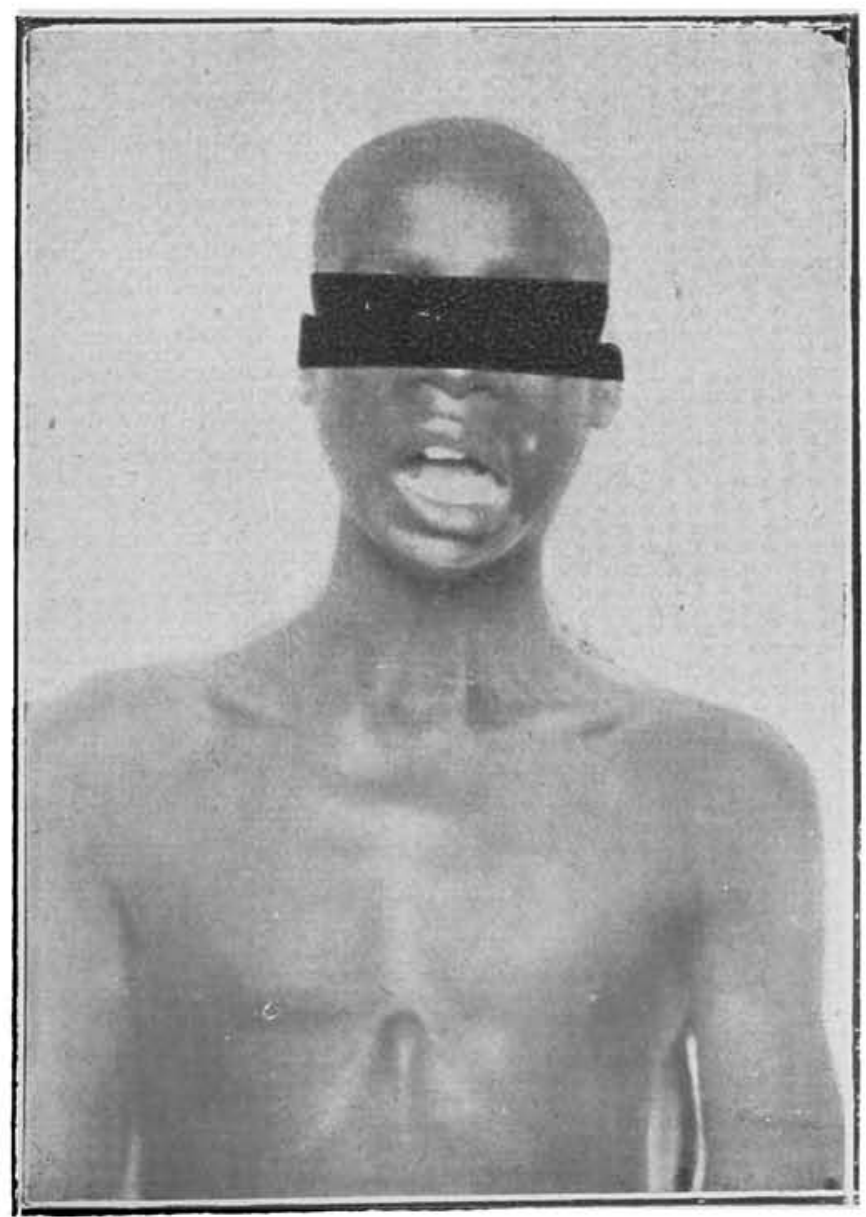

Photographia n. ${ }^{o}$ 3: - Desvio da lingua para a esquerda. Menor saliencia do Esterno-Cleido-Martoidêu homolateral. (26-VI-1923).

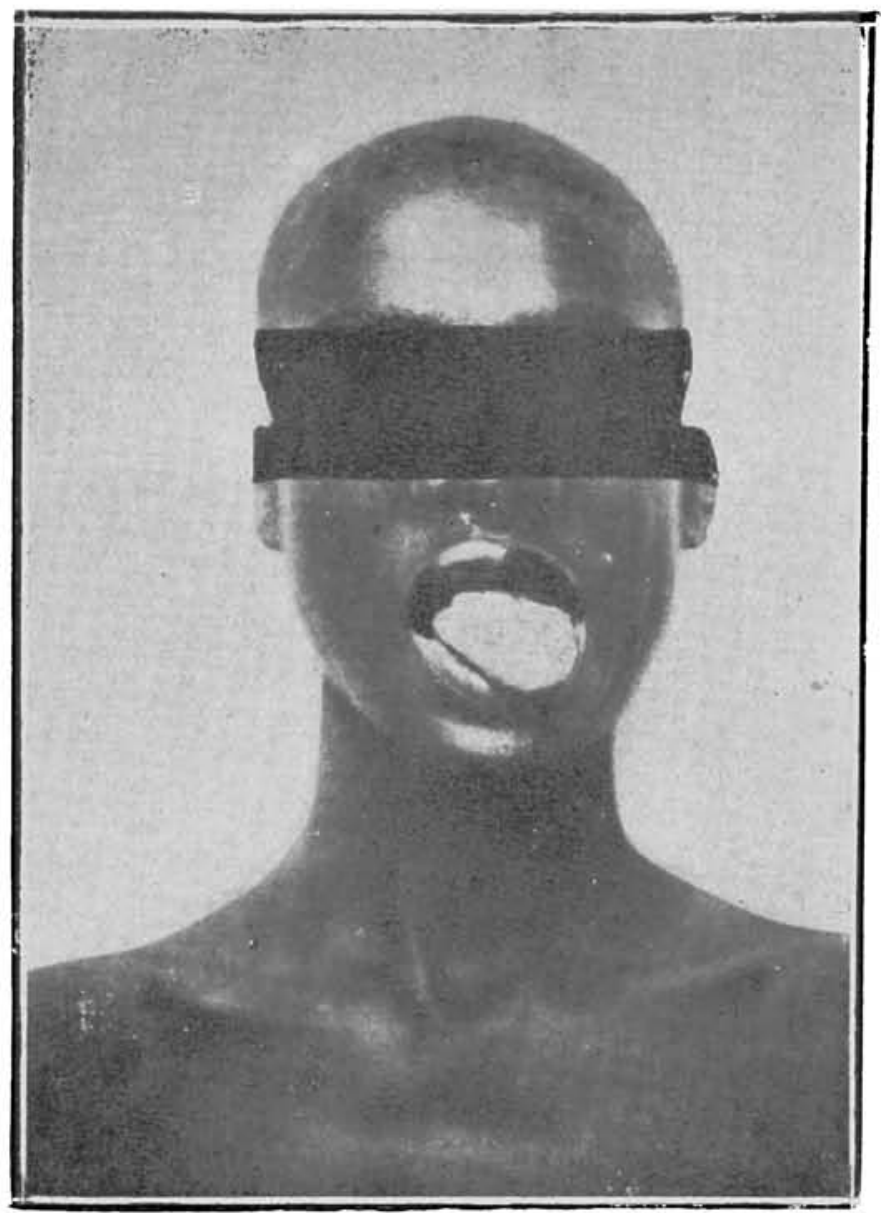

Photographia n.' 2: - Desvio da bocca. Ausencia de contracção do cuticular direito. (20-VI-1923).

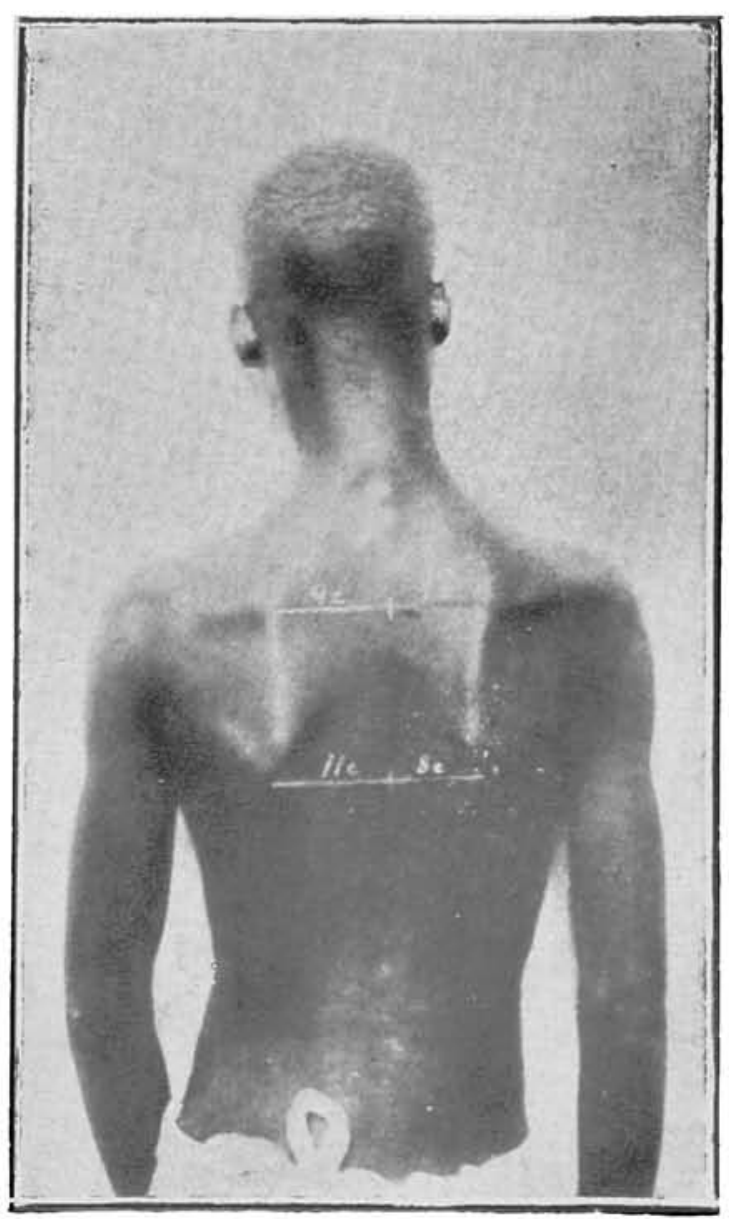

Photographia n.o 4: - Maior saliencia do omoplata esquerdo. Ligeira quéda e desvio para fóra. (26-VI-1923). 

ANTECEDENTES DE FAMILIA: - Paes fallecidos, não podendo precisar a molestia que os victimou. nem o tempo. Não tem irmão. Não sabe informar se sua mãe teve aborto.

ANTECEDENTES PESSOAR: - Teve sarampo e coqueluche na infancia. Nega qualquer antecedente venereo-syphilitico.

MOLESTIA ACTUAL: - Sua historia pregressa: - A 22 de malo do corrente recebeu, no meio de uma disputa, á distancia de 2 metros, um tiro desfechado por um dos contendores. Perdeu, immediatamente, os sentidos. Voltou a si, meia hora depois, segundo informações dos que lhe ministraram os primeiros cuidados. Que perdera sangue, e bastante, vermelho, rutilante, pela cavidade buccal e nada pelos ouvidos, soube mais tarde. Durante o tempo que esteve desaccordado não teve contracções, generalisadas ou localisadas. Sobre o apparecimento das perturbações de que é portador procurámos a sua elucidação, o que conseguimos, em parte, com grande difficuldade. Apuramos, assim, que uma accentuada dysarthria já era patente quando o doente deu por si, acompanahada de um desvio da bocca e dôres nas regiões facial e cervical desse iado. Sómente na manhan seguinte percebeu que a motilidade dos seus membros direitos, sobretudo a do superior, estava compromettida, quando, então, a dy sarthria ganhou em intensidade e ficou accrescida de uma dysphagia.

Procurando narrar os factos succedidos - e sua memoria era e é fiel - verificou a difficuldade qque encontrava para falar, com perturbação dos movimentos da lingua, no interior da cavidade buccal. Ainda nesse dia perdeu um pouco de sangue pela bocca.

ESTADO ACTUAL: - De mediana estatura e regular icomplleição muscular é o nosiso observado. Paniculo adiposo regularmente destribuido. Mucosas clinicamente exploraveis, coradas. Ganglios inguino-cruraes enfarctados. Difficilmente fala e sua voz é bitonal.

Cabeça: - Normal a conformação do craneo. Chama desde logo attenção a existencia, na parte inferior do sulco naso-geniano esquerdo - mais escavado que o seu homologo - de uma pequena cicatriz, arredondada. Além desta perturbação nenhum outro facto revela asymetria facial, no estado de repouso, não acontecendo o liesmo quando o doente. ri, fala, abre a bocca ou tenta assobiar. Nestas emergencias, porém, se instala um desvio para fóra e para baixo da comissura labial esquerda (ver photographia n.. 2), ao mesmo temipo que em rugas se escava a pırcão inferior da themitace homolateral e entra em contracção o cuticular, na região cervical do mesmo lado. Essises actos são seguidos de dôres idifusas, na face e no pescoşo.

Está perfeitamente integro o facial superior. São presentes e eemelhantes as rugas frontaes transversaes e verticaes provocadas. Os supercilios conservam o seu arqueado caracteristico. Não ha lagophtalmia, epiphora; tambem são negativos os signaes clinicos de Negro, Bell, Legender, Dupuy-Dutemps e Cestan e de Revilliod. Quanto an facial inferior observamos: ausencia de desvio do nariz e do mento, com igualdade das narinas. $O$ sulco naso-geniano esquerdo está mais accentuado, onde deiscrevemos uma cicatriz-ponto de penetracão da bała. Não ha flacídez da bochecha e está ausente o signal de Mingazzini. Desvio da comissura labial esquerda quándo o doente abre a bocca. A palpação da face mostra reacção muscular 
á esquerda, despertando, mesmo a superficial, phenomenos doloroecis. Não accusa seccura da lingua, hypo ou hyperacusia, nem retenção dos alimentos no sulco gengival direito. Reacção electrica normal. O facial direito reage bem:

$\mathrm{Ha}$ accentuado trismo.

Bocca: - Pequena amplitude no abaixamento do maxillar inferior, difficultando bastante o exame da cavidade buccal. Não accusa a lingua pesada, enchendo esta, mas informa que durante a mastigasão, ou quando procura articular palavras, sente, nesse orgam, accentuadas dôres. Eldema da face interna da bcichecha eisquerda. No fundo da cavidade buccal, deste lado, ha uma uliceração, de contornos irregulares, com edema ao redor.

Dentes em bom estacoo, alguns mal implartados, faltando, na arcada superior, em correspondencia ao ponto de penetração da bala, un premolar.

Lingua: - Coberta de uma espessa icamada de suburra, apresentase. no interior da cavidad buccal, com um ligeiro desvio para direita. Superficie lisa, sendo apagado o sulco mediano. No seu dimidio esquerdo, um pouco atrophiado, menos consistente, descorado, existia encravado um corpo duro, pequeno e branco. Ligamos este facto a ausencia recente do pre-molar, o que communicamos ao especialista. Este retirou da lingua a metade de um idente.

Movimentos da lingua: - De um modo geral estão todos limitados, de preferencia os de tateralidade á esquerda. O de elevação só é exeoutcido pela metade direita da ponta, que, assim, nos mostra sua face inferior. Não conseguimos os movimentos em idorso e em escavação mediana. A projeç̧ão, para fóra, está diminuida, evidenciando um desvio para esquerda, como mostra a phot. n." 3. Este desvio é real, independente do que soffre, nessa occasião, a commissura labial. Tomando-se, assim, um ponto de reparo fixo, como a arcada dentaria superior, vamos verificar que, emquanto a borda diseita da lingua, em projeıção, corresponde ao canino homolateral a esquerda alcansa o 2. premolar. A photographia n. 3 micstra que no tado 'direito ha um esipaço separando a comissura labial da borda direita da lingua.

Diminuição accentuadissima da exicitabilidade da metade esquerda. Salivasão abundante. Saliva alcalina e vilicosa.

Gustação: - Normal no dimidio direito, para o salgado, doce, azeđ̃o e amargo; um pouco attenuada no esquerido á percepção do doce, la região da, ponta.

\section{Exames feitos pelo Dr. Moreira}

1. ${ }^{\circ}$ exame - 16-6.

E.dema accentuado do véo do paladar, mais do lado esquerdo, alcancando, homolateralmente, a bochecha, pharynge e larynge. 0 corpo extranho encravado na lingua e a ulceração que disecrevemos na cavidade buccal foram verificados pelo especialista. Accentuado trismo. Immcibilidade do véo do paladar, nn seu lado esquerdo e ligeiros movimentos na metade opposta. Uvila na linha medina. Paralysia compieta, em posição cadaverica, da corda vocal esquerda. Paralysia da arythnoide do mesmo lado. Anesthesia laryngo-pharyngovelo-palatina.

2. ${ }^{\circ}$ exame - 19-6.

Os meimos factos foram observados.

3. ${ }^{\circ}$ exame - 21-6. 


\section{$1 / 5^{\prime \prime} \rightarrow$}

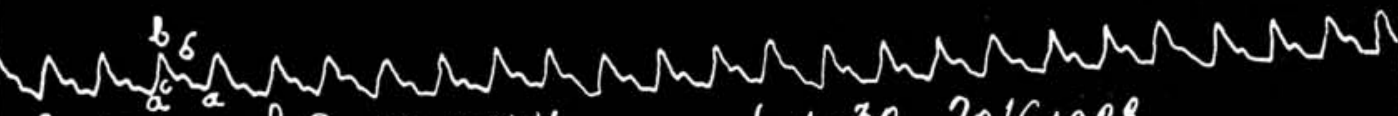
Sentado. \&.8 za wo. Homs decto 3020161929

Graphico n. $0^{\circ}$

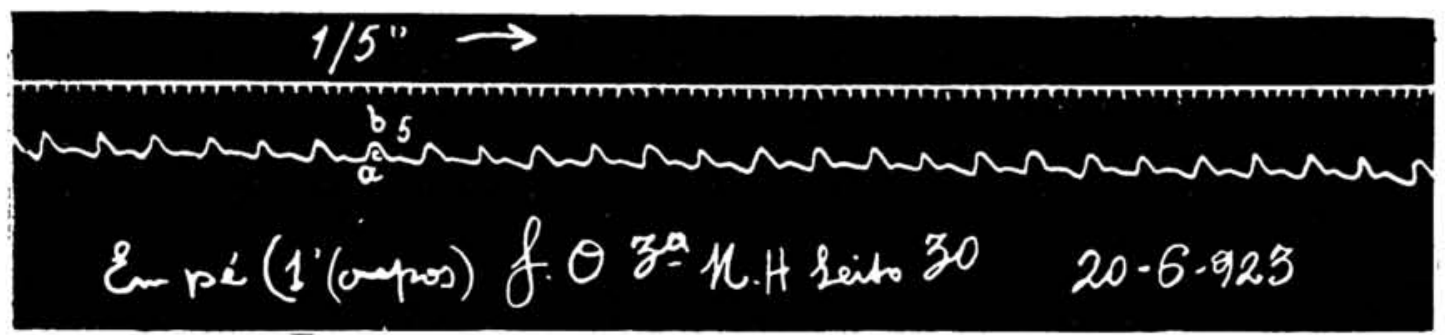

Graphico n. $0^{\circ}$

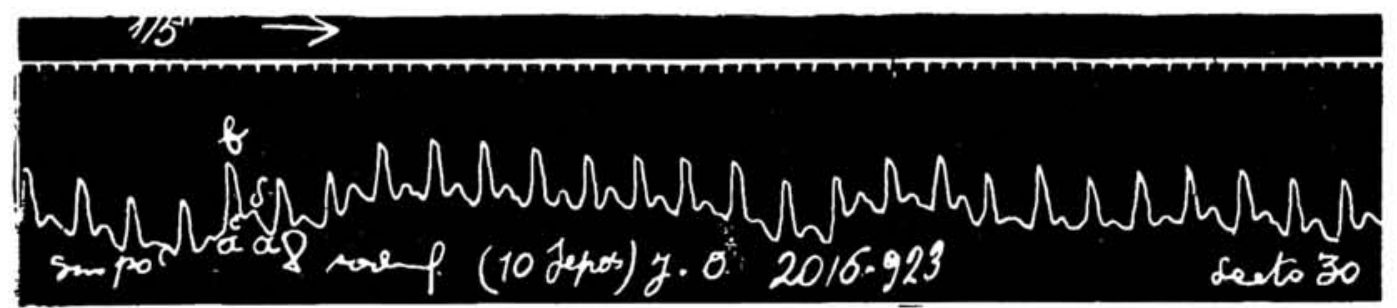

Graphico n. ${ }^{\circ} 3$

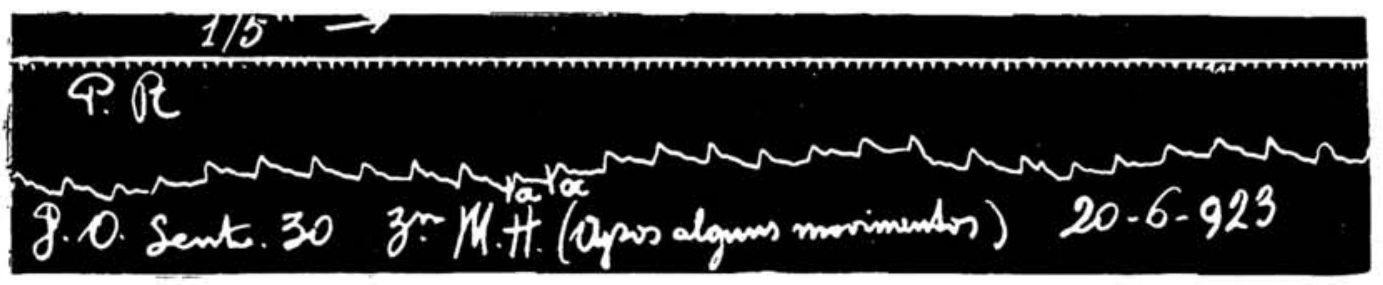

Graphico n.' 4

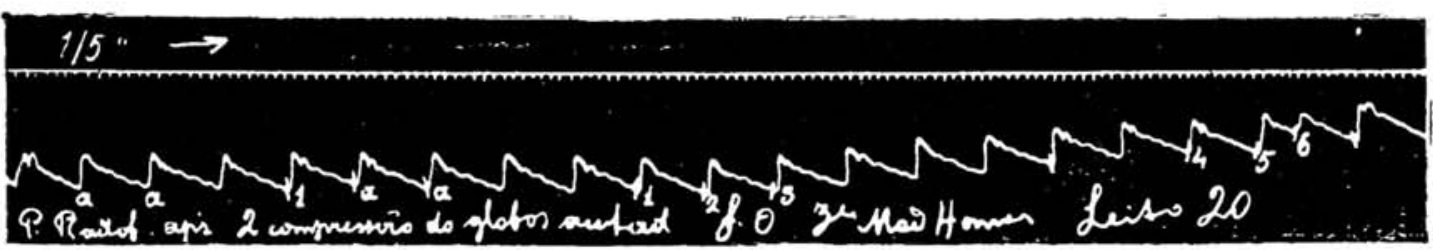

Graphico n. 5 

Melhoria do trismo e do edema. A corlda esquerda continua paralysada, um pouco encirvada para dentro. Ligeiros movimentos ao nivel da arythnoide e da parte posterior do véo do paladar. Anesthesia persistente.

4. ${ }^{\circ}$ exame - 23-6.

Como unica differença do exame anterior resalta a diminuição do edema.

Os exames feitos em 25 e 26 nada revelaram al'ém dos factos observadios no ultimio.

$7 .^{\circ}$ exame - 6-8.

Diminuição da paralysia do véo. Persistencia da hemi-anesthesia verificada. Paralysia da corda e da lingua do lado esquerdo.

Olhos: - Conjunctivas oculares coradas. Musculatura extrinseca normal. Reflexo da cornea presente. Solbre o estado da musculatura intrinseca e outros pormenores, diz o exame feito em 23-6 pefo Dr. Pereira Gomes: ligeira anisochoria, com pupilla de OD maior; reacções pupillares normaes de $\mathrm{OE}$ เe um pouco diminuidas de OD; meios coulares e muisculatura externa normaes. Não ha dipilopia. Fundi: OD -hypperemia venosa; OE normal. Visão normal de AO.

Nariz: - Nada de anormal. Reflexo nasall presente.

Ouvidos: - Normal - 0 exame feito em 27-6 nada miostrou de pathologico. Não ha anesthesia do pavilhão da orelha; é negativo o signal de Escat.

Pescoço: - A inspecção geral, em repouso, visto o doente pela frente, mostra uma diminuição da saliencia dos feixes esterno-cleidn-occipito-mastoidêos esquerdos, particularmente da do esternal (r.hot. n. ${ }^{\circ}$ 1). Está um pouco mais esicavada a fossa supra-cilavicular do mesmo lado; onde o trapezio, descenido da extremidade cephalica para ganhar o omoplata o faz menos suavemente, perdendo o seu arqueado. O abaixamento forçado do maxillar superior promove a contracção das fibras do cuiticular esquerdo, facto não obsiervado á direita. Desloca, o doente, facilmente a cabeça para o lado direito, embora na execução desse movimento soffra dôreá fortes na nuca. Estão normaes os outros movimenntos. A escavação da fossa supra-claviciular esquerda mais se accentúa com os movimenitos de लil:evação da cintura escapular e de abducção do braço. Não ha projecçâo clavilcular - a descripta pseudo-hypertrophia.

A palpação mostra a existencia na face posterior, lado esquerdo, de uma zona saliente, com reacção muscular e dolorosa. Flacidez, embora pouco patente, dos musculos trapezio e esterno-cleido-occipito-mastoidêo. Ausencia de enfartamentos ganglionares.

0 exame electrico, feito pelo Dr. Scaff em 23-6, mostrou reacção bem diminuida de amlbos. $O$ trapezio direito possue contracção mais brusca e que se efféctua de uma só vez. Contracção vermiculạr do feixe superior do trapezio esquerdo.

A excitação do esterno-cleido direito produz immediata contracção dos seus dois ramos, com deñvio da cabeça. Pou'co nitida é a contração para o musculo do lado opposto.

Thorax: - Conformação normal, visto pela face anterior. Paniculo adiposo pouco desenvolvido. São iguaes as distancias acromio-claviculares. Parece haver uma ligeira queda da cintura escapular esquerda. O thorax, estuidado pela sua face posterior, não revela desvio da columna vertebral, nem atrophia das moussas musculares supra e infra-espinhosas. $O$ omoplata esquerdo mostra-se ma1s sailente e um pouco desviado para fóra (phot. n. 4). Acreditamos 
não correr esse desvio por conta da inclinação que o doente im. primiu á extremidade cephalica no momento de ser photographado, pois certas medidas apanhadas en: perfeito estado de repouso nos a utorisam a assim pensar. Vejamos:

a) Da parte media da borda espinhal de um omoplata ao ponto homologo de outro vae uria distancia de 15,5 cent., dos quaes 9 correspondem ao espaço inter-escapulo-vertebral esquerdo, e 6.5 cent. ao direito.

b) De um angulo inferior ao outro verificamos 19 centimetros, sendo 11 para a distancia que vae do lado esquerdo á columna e o restante á opposta;

c) De um angulo superior ao outro medimos 16 centimetros, sendo 9 para o lado esquerdo e 7 para o direito.

Apparelho respiratorio: - Typo respiratorio thoraco-abdominal. Movimentos respiratorios de regular intensidade, bem rhythmados, em numero de 20 por minuto. A palpação não desperta dôres nas espaduas e regiões claviculares. A percussão mostra ligeira sub-masissez no apice direito, unde a escuta revela uma respiração rude, soprosa, com a phase expiratoria prolongada. Signaes evidentes de bronchite diffusa. Tosse rouca e pouca expectoração.

Aparelho-cardio-vascular: - Area de macissez cardio-aortica normal. Ictus cordis n. ${ }^{\circ}$. Entiecôsto esquerdo. Bulhas bem audiveis. Pulsos isochronos, rapidos, rythmados e de media intensidade. Mostram-se excessivamente iustaveis, como revelam os exames, digital e esphygmographico, feitus.

1. ${ }^{\circ}$ exame - 16-6.

Em decubito dorsal - 96 .

Sentado - 120 .

Em pé - 124 .

10 minutos depois:

Em decubito dorsal - 96 .

Após compressão de dois minutos dos globos oculares -80 .

2. ${ }^{\circ}$ exame - 20-6.

1) Graphico numero 1 - sentado. Pulso regular intensidade, hem rhythmado, com uma frequencia de 90 pulsações por minuto.

2) Graphiso numero $2-1$ minuto depois. Frequencia maior - 105; amplitude menor e rhythmo normal.

3) Graphico numero $3-10$ minutos depois. Frequencia de 110, amplitude maior e shyt'lno sormal.

4) Graphico numero 4 - após alguns passos. Frequencia de 95, amplitude pequena e rhythmo normal.

5) Graphico numero 5 - após 2 minutos de compressão dos globos oculares. Queda do pulso para 50 (reflexo oculo-cardiaco muito demonstrativo), augmento da amplitude e apparecimento de ondulações catacroticas. Arhythmia.

3. ${ }^{\circ}$ exame - 14-8.

6) Graphico numero 6 - em decubito dorsal. Pulso de regular intensidade, bem rhythmado ,com uma frequencia de 80 pulsações sor minuto.

7) Graphico numero 7 - sentado - 1 minuto depois. Diminuiçło da amplitude e augmento da Prequencia para 100.

8) Graphico numero $\&$ - sentado -2 minutos depois. Frequencia anterior no inicio do traçado $e$ um augmento para 105 na por- 


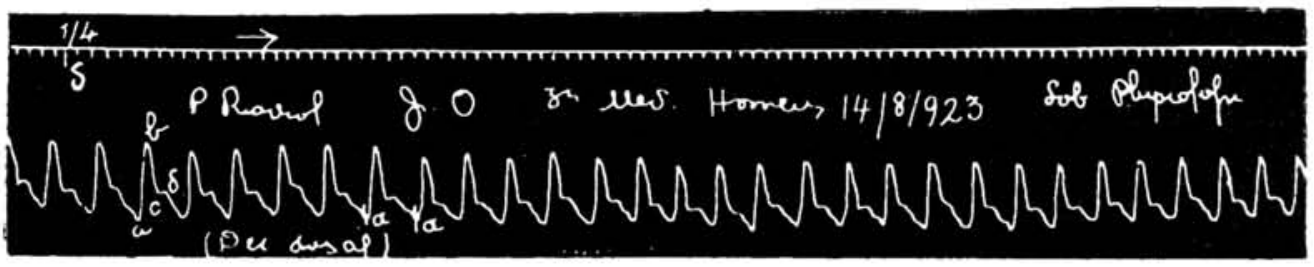

Graphico n. ${ }^{0} 6$

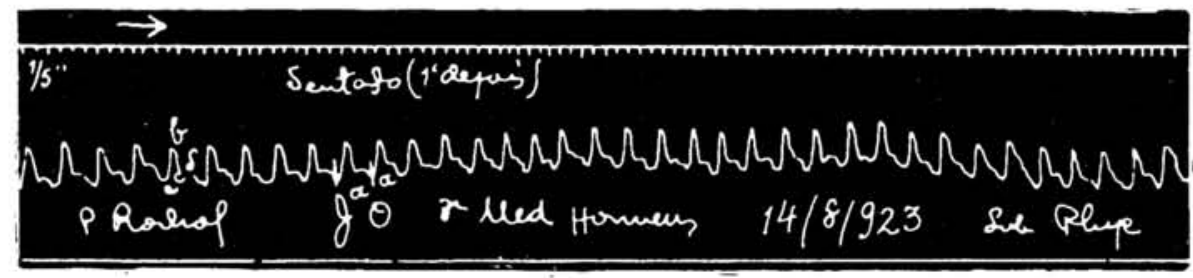

Graphico n. ${ }^{\circ} 7$

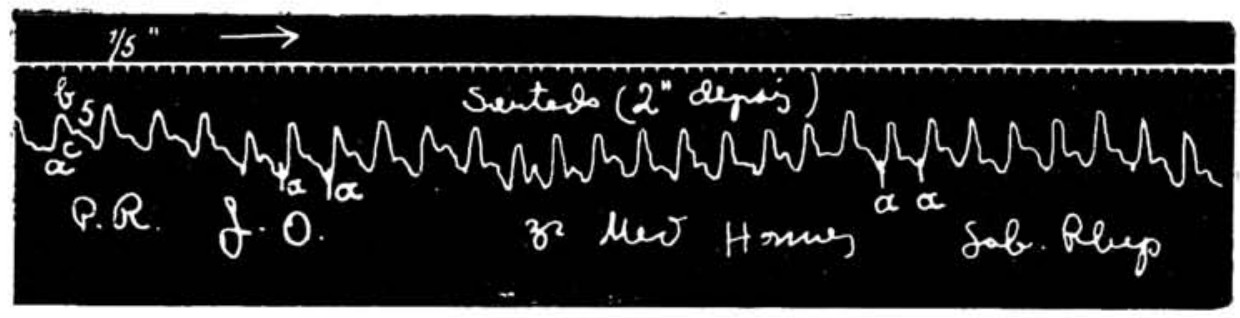

Graphico n. ${ }^{\circ} 8$

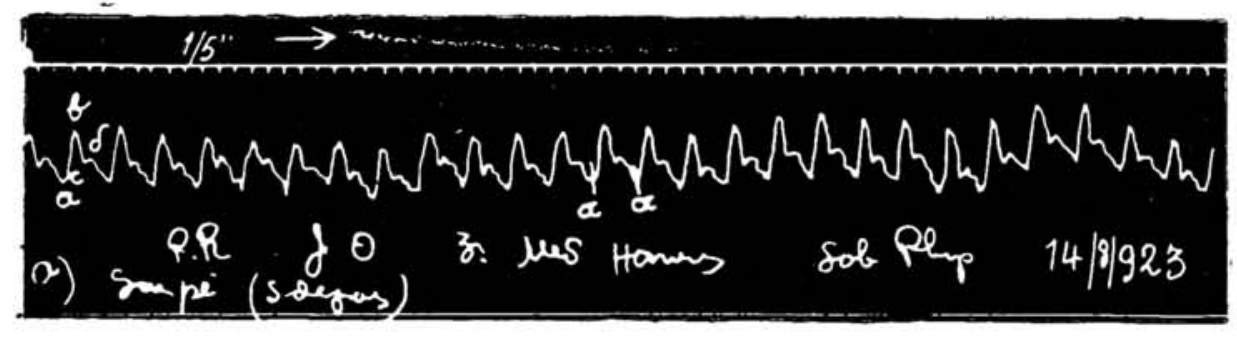

Graphico n.* 9

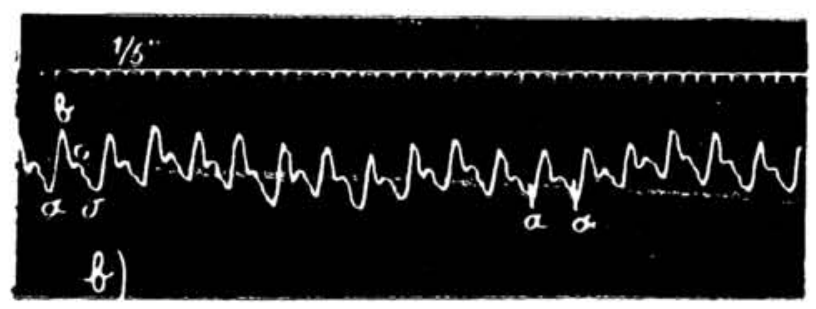

Graphico n. 10 

Gão final. A regularidade do esphygmogramma está alterada pela eurva pneumographica que nelle go inscreve.

9) Graphico numero 9 - em pé - 5 minutos depois. Augmento da tachycardia para 110, com a mesma influencia do rhythmo respiratorio. Os graphicos 10 e 11 uada mais são que continuação do numero 9. Revelam a mesma frequencia, amplitude e rhythmo.

12) Graphico numero 12 - auós 2 minutos de compressão dos globos oculares. Appresenta um augmento da amplitude com diminuição da frequencia parı 75. O rhythmo parece normal.

13) Graphico numeo 13 - após 2 minutos e 69/5 de compressão. Queda para 55, surgindo, já, uma arhythmia.

14) Graphico numero $14-$ após 4,5 minutos de compressão. Ha no inicio uma elevação a 60 e depois uma volta a 55. Arhythmia existe ainda, mas não de uma maneira clara, como nos revelou o braphico numero 5.

Abdome. Os meios de exame nada ensinam de interessante. Os reflexos estudaremos abaixo.

Apparelho digestivo. Lingua saburrosa. Não ha dysrorexia, vowito, nem polydipssia. Evacuações regulares. Dysphhagia não dolorosa para todos os alimentos, sobretudo aos liquidos. O doente deu a entender que os alimentos eram deglutidos com certa difficuldade, accusando á altura da cartilagen ‘ cricoide a região onde tinha a sensação de sua parada. Seu visinho de enfermaria insistiu, quando o interrogamos, em torno desta perturbação. Fizemos o doente deglutir agua e observamos a veraciciade do facto. $\mathrm{O}$ acto deglutitorin pra interrompido na sua phase esophagiana, ao mesmo tempo que uma tosse surgia (tosse de deglutição de Vernet?) Não notamos refluxo dos alimentos, pela bocca ou pelo nariz - logo havia operculisação rhino-pharyngéa.

Systema nervoso. Aprisentava o doente, quando deu entrada no serviço clinico do Prof. Pires de Campos, uma hemiplegia direita : arcial e incompleta, com o membro superior ligeiramente contra$\mathbf{c}^{+}$urado em flexão, sem conseguir movel-o, e a perna descrevendo um arco de circulo, quando caminhava. Cedeu a contractura alguns dias depois, como demonstra a phot. n. 1, apanhada em 20-6. Sensibilidade superficial din':nuida en todas as suas modalidades, no lado direito. Hyperesthesia da hemiface esquerda.

Reflexos. Os profundos ou tendinosos estavam exagerados no lado. direito. Assim notamos:

1) Mentoniano - augmentado.

2) Biceps - augmentado.

3) Longo supinador - augmentado.

4) Escapulo humeral - augmentado.

5) Carpo-metarcarpiano - ausente.

6) Triceps - normal.

7) Patellar - muito vivn.

8) Achilliano - muito vivo.

9) Clonos do pé e dansa da retula.

Reflexos cutaneos e mrcosos:

1) Da cornea - presente.

2) Pharyngêo - ausente.

3) Véo do paladar - ausente.

4) Escapular - ausente.

5) Epigastrico - ausente. 
6) Abdominaes - ausentes.

7) Cremasteriano - ausente.

8) Glúteo - ausente.

9) Signal de Babinski - pela excitação da planta do pé, pela manobra de Oppenheim $\epsilon$ pela Gorỏon (reflexo flexor paradoxal).

Não ha perturbação baresthesica, nem da altitude segmentar. Não observamos dysmetria, asynergia, tremores, catalepsia e estado vertiginoso.

O exame electrico, feito em 23-6 pelo Dr. Scaff, revelou menos excitabilidade do lado direito. Ausencia de R. D.

Normaes os reflexos do lado esquerdo.

As perturbações sensitivas e motoras soffreram modificação com o evoluir da molestia. Fioje o dounte caminha com facilidade, fala melhor e apresenta bem diminuido o desvio da comissura buccal. Um mez depois de internado suas mãos foram séde de intensa descamação, ao mesmo tempe que atrophiado ficou seu membro supei icr direito. Os reflexos tendinosns ainda estão vivos, embora falte a extensão do grande artelho. Ligeiros tremores são perceptiveis em eubstituição á dansa da rotula e o clonos do pé.

A sensibilidade tactil está presente e normal, ao passo que a thermica e dolorosa se mostram diminuidas no membro inferior direito, na face externa da coxa e na perna. A dissolução syringomyelica existe, tambem, no memlro superior direito. Ligeira hyperesthesia da hemi-face esquerda. Lo dia em que entrou até 7 de agosto ultimo J. O. teve sua temperatuı a acima da normal, com elevação vesperal. Foram ainda feitos os seguintes exames, como meios auxiliares do diagnostico:

Raios X: - A radiogrsphia N. 1 , de perfil, feita pelo Dr. Barros, mostra a existencia de um corpo opaco, lateralmente situado á columna vertebral, á altura da $2 .^{\mathrm{a}}$ cervical, e um pequeno fragmento ahaixo do angulo do maxillar inferior. A N.' 2, no sentido posteroanterior, mostra a bala occupando o lado esquerdo.

R. de Wassermann - Positiva $(+)$

Exame de urina: - Nada ne anormal.

Exame de escarro: - Negativo.

Resumo das perturbações apresentadas por J. O. actualmente.

\section{LADO DIREITO}

1) - Paresia parcial, incompleta.

2) - Hypo-esthesia, typo syringomyelico.

\section{LADO ESQUERDO \\ 1) - Paralysia do $\mathrm{X}$ \\ 2) - Paralysia do XI \\ 3) - Paralysia do XII \\ 4) - Irritação do VII \\ 5) - Irritação do V}

Como decorre da observação, o nosso doente traz o conjuncto clinico de syndromo alterno. typo Jf.ckson complicado. 0 exame, de facto, revela uma modificação na esphera sensilivo-motora de um iaro, e de outro, uma dylsfunçãa se evidencia no tocante os papeis ontorgados em nossa economia a 5 nervos encephalicos.

LADO DIREITO: - Basta meditar um pouco em torno da sua marcha disforme, da hypereflexia tendinosa, traductora da libertação espinhal do dominio cortical e da ireflexia cutanea, do lado direito. 


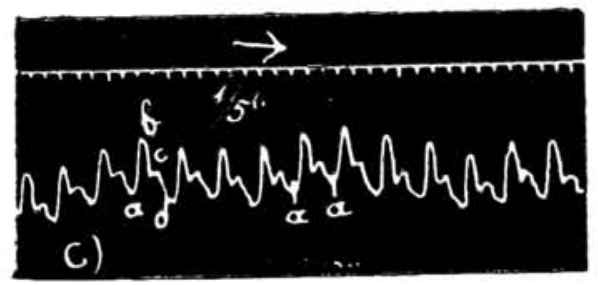

Graphico n. ${ }^{\circ} 11$

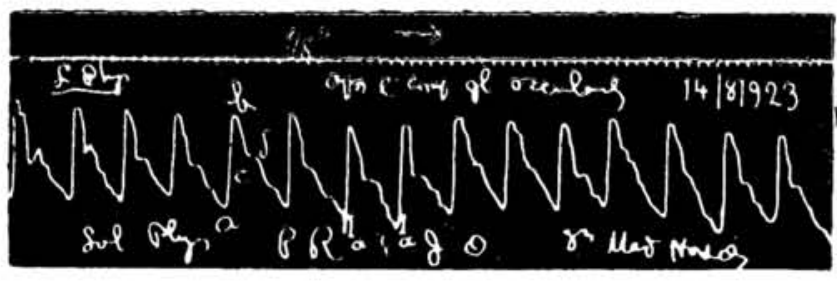

Graphico n.' 12

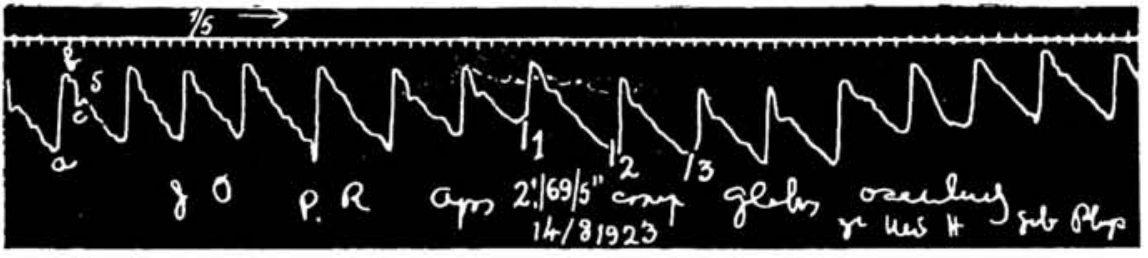

Graphico n." 13

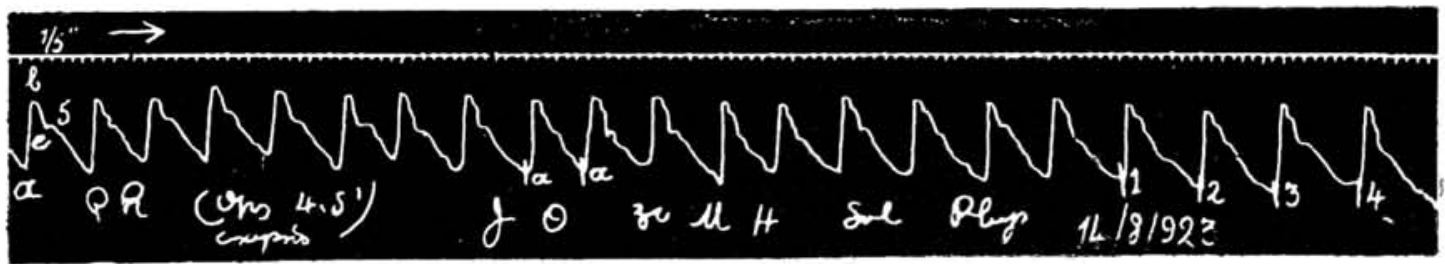

G:apisice 1.. 1.; 

para que, sem mais detença, seja admittido o compromettimento do contingente cortico-meduilar, que se origina na area giganto-pyranidal esquerda. Que tainbem a via sensitiva não continúa normal, mas em estado deficiente. no tocante a transporte da sensibilidade superficial, ao menos nas suas formas thermica e dolorosa, attesta a hemi-hypoesthesia syringomyelica.

LADO ESQUERDO: - Como complemento, factor que caracterisà o syndromo alterno, notamos, aqui, alterações interessantes, que merecem consideradas de perto.

I) - Paralysia do $\mathbf{X}$ : - $\mathrm{O}$ vago, nervo mixto, tem sua origem real na porção media do nucleo ambiguo, esta longa columna de substancia cinzenta que, no bulko, é repr'sentante da cabeça do corno an$t \in$ rior, decapitada pelo entrecruzanitento motor pyramidal. Suas fibras motoras abandonam a caixa craneana pelo buraco despedaçado posterior, reunem-se ás do ramo interno do espinhal, formando o tJonco vago-espinhal. Suas fibras sensitivas, com origem nos seus ganglios têm como ponto de terminação a parte inferior da aza cinzenta, columna que o entrecruzamento sensitivo forma pela decapitação do corno posterior.

O quadro abaixo resume as perturbações da paralysia do pneumogastrico:

A) SYNDROMO MOTOR

\section{B) SYNDROMO SENSITIVO}

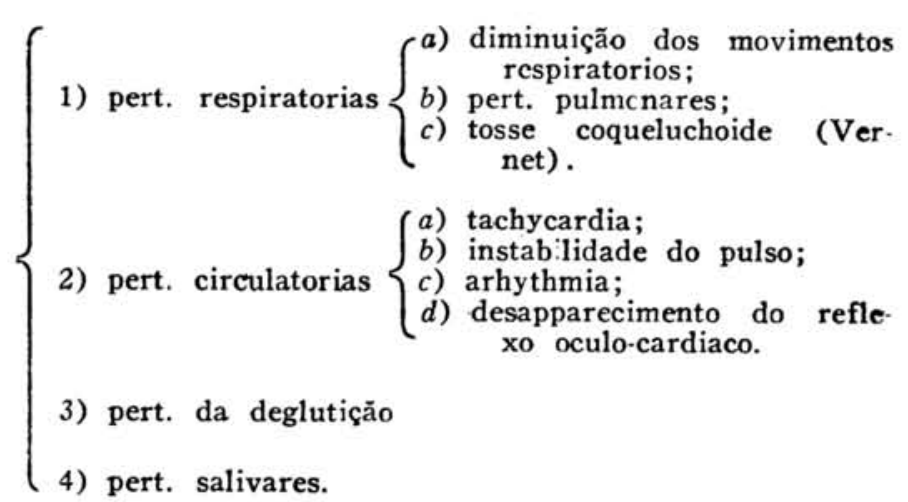

A) Syndromo motor.

1) Pert. respiratorias: - Apresentou o doente, durante um longo espaço de tempo, tosse rouca, hypersecreção das vias respiratorias, expectoração difficultada pe:as paralysias presentes e signaes de bronchite diffusa. Inclinamos a incriminar uma infecção intercorrente ,a grippe, que então cam l’eava em nossa cidade, como responsavel pelo quadro acima, considerando o seu inicio e a marcha seguida.

2) Pert. circulatorias: - Estas collocamos ás expensas de uma paralysia do vago. Registamos: ligeira tachycardia, notavel instabilidade do pulso, arhythmia e o reflexo oculo-cardiaco de AshnerMiloslawich.

Melhor que qualquer argumentação, demonstram estes factos os nossos graphicos. Os Ns. 1 e 2 falam em pról da instabilidade, que, digamos de passagem, mais se evidenciava nos momentos de troca de posição. $O$ n. 5 inscreve o reflxo oculo-cardiaco, após 15 m1- 
n!itos de repouso, quando as ondulações esphygmicas se mostravam eom a frequecia das do graphico n. 1.

Além de bradicardico o pulso $\epsilon$, agora, arhythmico. Por este lesvio da normalidade responsabilisamos uma alteração da funcção chronotropica cardiaca, ou estimulogenica, como bem definia o Prof. Miguel Pereira. Julgamos, assim, jdentificar no graphico n. 5 uma arhythmia sinusal, pois acreditamos que as precoces ondulações $\mathbf{x} \Theta \mathbf{J}$ năo correm por conta de extra-systoles, visto não haver equivalencia entre duas revoluções nardiacas e a somma dos espaços 1-2 e 2-3. Falta a pausa compensadiora de Marey, que sempre acompanha os accidentes extra-systolicos.

Como interpretar esse reflexo trigemeo-vago, paradoxal aqui, por sc:r a sua ausencia e não a sua presença a traducção da paralysia do pneumogastrico? A iiffluencia da compressão dos globos oculares snbre o rhythmo cardiaco tem sido objecto, ultimamente, de acurados estudos dos clinicos $\epsilon$ physiolngistas. Petzetakis estudou-a elec!rographicamente, utilisando nas suas pesquizas o compressor manometrico de Roubinowitch. Outros trabalhos têm sido publicados, como os de Dagnini, Danielopulo, Lewis, Laubry e Harvier, Pezzi e Clerc, etc.

O Prof. Pace (1) estudando os dois syndromos de paralysia do vego, aborda, entre outras, a questão do reflexo oculc-cardiaco nos casios de ferimentos unilateraes. Diz que Collet e Petzetakis obtiverem pela compressão do globo ocular do lado illesc um reflexo normal ou positivo, ao passo pela feita no globo do lado doente a sua inversão. Procuramos verificar esse facto em nosso doente e fomos encontrar o reflexo positivo, e muito, após compressão isolada $\theta$ bem espaçada deste ou equelle globo ocular. Duas perguntas achamos opportunas: a) como interpretar em J. O. a bradycardia pela compressão do lado esquerdo, uma vez levada em consideração o registo de Collet e Petzetakis?; b) como conciliar a presença desse signal de hypertonia do vago com outros evidentemente traductores da sua paralysia? Respondemos ás duas, lembrando a existencia de fibras internucleares, ao nivel do bulbo, entre os centros motores do vago, donde a possivel diffusão de uma incitação chegada. Aquella trazida pelo trigemeo esquerdo no primeiro caso, ou por ambos no segundo, aproveitaria o vago direito, em estado hygido, como via centrifuga. Essas fibras internucleares, myelencephalicas, garantem, ao nosso ver, a possibilidade da presença do reflexo por compressão do ou dos globos oculares, $\mathrm{n} \cap \mathrm{s}$ cascis de lesão unilateral do $\mathrm{X}$ par. Não acreditamos que assista razão a Petzetakis para affirmar a falta do reflexo, ou a inversão pela compressão homoteral no nervo lesado.

Poderá a bradycardia, signal de hypertonia do vago, ser, no caso que estudemos, explicada por uma dissociação do syndromo motor, talqualmente o fez Pace em relação ao syndromo sensitivo? As fibras afferentes ao coração poderão estar irritadas, quando outras, do mesmo tronco são, positivamente, séde de um estado hypotonico?

Não acreditamos, e contra essa hypothese falam nossas experimientações (2) e a clinica nas mãos de Moure, Liébault e Canuyt (3).

(1) Su gli effetti della sezione del vago sinistro in una donna. Studium - 5-5-922.

(2) Fim torno da physiologia do tronico vago-espinhal. - 1923.

(3) Pathologie de gúne du larynx et de la trachée. - 1920. 
Demonstramos em um trabalho recente a existencia, no cão, de uma verdadeira systematisação no tronco vago-esipinhal, eln virtude da qual as fibras afferentes ao coração e á larynge seriam periphericas, e esses autores trazem documentos indubitaveis. Visto isso, como admittir a destruição das fibras profundas, com apenas irritação das superficiaes?

Esta observação nega a segunda hypothese aventada para explicar a bradycardia, reforçando, indirectamente, a primeira. Em favor desta ultima ainda trazemos uma outra argumentação. Em 1914, Morat e Petzetakis deram ao vago direito um accentuado papel soibre a producção da fibrillação auricular. Gauter e Zahn foram alem, collocando sob as ordens deste nervo o funccionamento do sinus auricular de Keith e Flack, ao passo que o esquerdo teria seu dominio reservaldo ao nó de Aschoff-Tawara. Vê-se, assim, que a funcção chronotropica, ou de excitação, obedeceria ao vago direito e a bathmotropica ao esquerdo. Esta concepção confirma a nossa hypothese acima, de ser o vago direito, integro, o responsavel pelo exagerado reflexo oculo-cardiaco, pois a arhythmia que registamos é do typo sinusal, traduz uma alteração funccional do sinus reunens.

3) Pert. da deglutição: - Positiva, não dolorosa, no momento esophagiano, de preferencia aos elimentos liquidos. Será a dysphagia causada pela hemivelo-glossoplegia? Não, porque, então, do veria surgir na pre-deglutição, na phase buccal.

A dysphagia era seguida de tosse, não occasionando refluxo dos alimentos. Foi a primeira pert. a desapparecer.

4) Pert. salivares: - A paralysia do vago, diz Pace, é acompańhada de seccura da bocca, traduzindo a hypersecreção um estado hypotonico. Como explicar em nosso doente este flagrante contraste? Recorremo-nos a Guillaume (1), entre outros, que admitte a secreção das glandulas salivares correndo por conta de fibras do systema para-sympathico incluidas no tronco do facial e do glossopharyngêo. Outras fibras existem, agindo sobre as glandulas, emborá em menor escala, provinientes do systema thoraco-lombar. Ha normalmente um verdadeiro estado de equilibrio entre ellas, que rompido, traz o estado hypertonico de umas, com estado opposto de outras. Não haverá em J. O. lesão das fibras do systema sympathico verdadeiro?

B) Syndromo sensitivo.

1) Anesthesia palato-pharyngo-laryngéa. - Esta alteração da sensibilidede fez parte do laudo do especialista. Qual triade sensitive attesta a lesão das fibras bulbopetas do vago, uma vez acceita a moderna concepção de Vernet, que, para sempre, mostrou a sua interferencia na innervação do tracto palato-pharyngo-laryngéo, afastando o glosso pharingeo e o trigemeo?

2) Signal do trago ou de Escat. - Consiste na anesthesia de uma região circular, de 4 a 5 centimetros de diametro, tendo como eentro o conducto auditivo externo. Traduz paralysia do ramo auricular do vago de Arnold ou da fossa jugular de Oruveillier. Negativo em nosso doente.

(1) Le sympathique et les systêmes associes. - 1922. 
Pace cita ainda, como lesão do vago, uma dôr, expontanea ou provocade pela compressão de larynge e uma tosse, coqueluchoide, pela pressão sobre a cartilagem thyreoide, ou, como quer Vernet sobre o angulo naxiliar do evierno-cieldo-occipito mastoidêo. Eśses phenomenos traductores, como é corrente, de uma irritação dos filetes sensitivos do vago foram pelo autor italiano registados em uma doente que soffrera seç̧ãn total do vago esquerdo.

Como explicar esta irritação vago-laryngéa implantada em um terreno anesthesico? Pace respondr a esta questão pela possivel disssociação sensitiva no territorio laryngêo, estando abolida a sensibilidade directa e exaltada a rellexa. Admitte, apoiado na opinião de Massci, a anesthesia pela lesão das fibras recurrenciaes, séde de rapida degeneração walleriena e a dôr e tosse pela irritação dos filletes da extremidade central do vago seccionado, onde pode haver incompleta degeneração.

o nosiso observado nunca apresentou essas perturbações.

II) - Paralysia do Xi - Nerve essencialmente motor, tem sua or:gem real na parte media do nucleo ambiguo, para suas fibras bulhases ,ou do ramo interno e no corno anterior da medulla cervical, porção alta, para as espiahaes, ou do ramo externo. Quando paralysado, apresenta:

1) Ramo interno - Hemiplegia laryngo-velo-palatina.

2) Ramo externo - Esterno-cleido-trapezioplegia.

1) Hemiplegia laryngo-velo-palatina: - Afastada por Vernet (1) a interferencia do VII par na innervaçâo do véo do paladar e perfejtamente acceita a opinião, por elle, Moure, Liébeult, Canuyt e uutros apregoada, da destribuição aqui, como a musculatura intrinstca laryngéa, pelas fibras bulbares do nervo accessorio de Willis, fica perfeitamente assente que o seu syndromo paralytico se resume en uma hemiplegia laryngo-velo-palatina homolateral. Eis o syndromo de Avellis, do qual é portador o nosso doente.

Considerando o ponto alto da emergencia das fibras afferente ao véo do paladar, vê-se, para sua producção, a necessidade de uma lesão na parte superior co vago.

2) Esterno-cleido-trapezioplegia: - Dois musculos, com inserç̃es cephalo-thoraxicas. recebem, ao lado das fibras enviadas pelos p:imeiros pares racheanos cervicaes, innervação proviniente do ramo espinhal do XI par. São elles o isterno-cleido-occipito-mastoidêo e o trapezio.

Os signaes denunciadores de uma paralysia destes são, transcrevendo o Prof. Aloysio de Castro (2):

“a) projeç̧ão da clavicula no lado da paralysia, dando-lhe o aspecto de hypertrophia - pseudo-hypertrophia clavicular;

b) formação de uma escavação profunda na região supra-clavicular, visivel em qualquer attitude. especialmente nos, movimentos de elevação da espadua c abduçãa do braço;

c) menor relevo das massas do trapezio e do esterno-cleidomastoideu;

(1) De l'innervation du voile du palafs. - Rev. neur. - 1918.

(2) Notas e observações clinicas. -1920. 


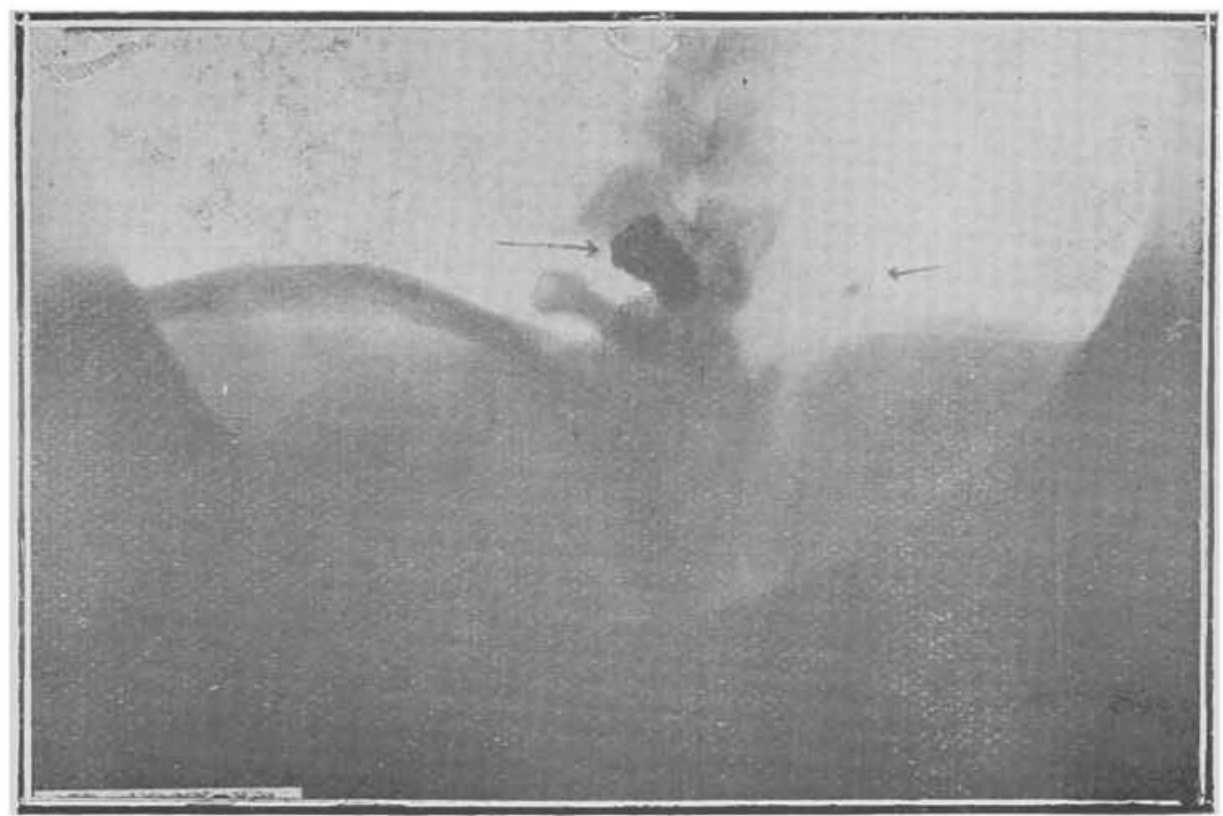

Radiographia n.` 1: - Localisação da região occupada pela bala

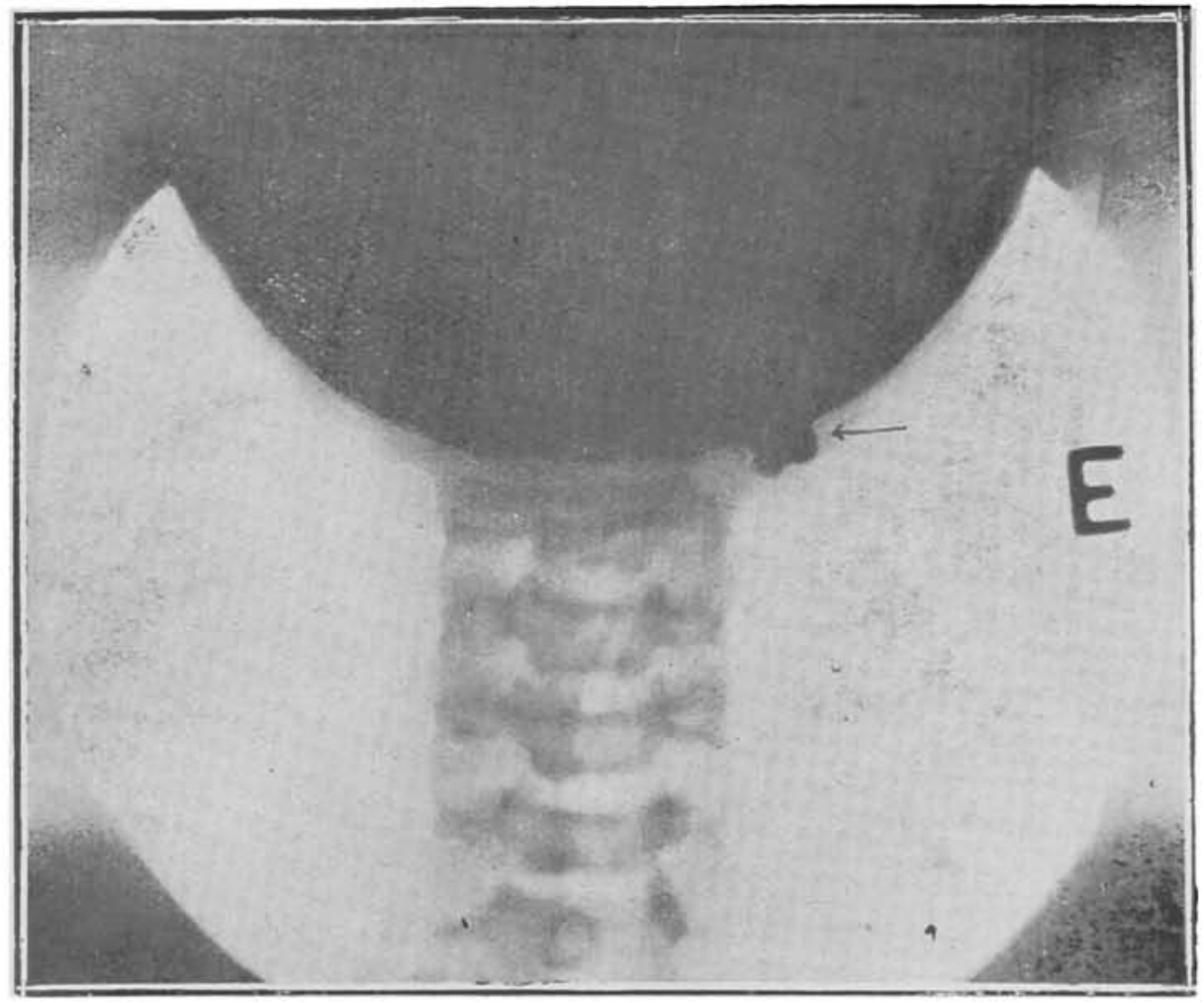

Radiographia $n .^{\circ}$ 2: - Foi apanhada no sentido postero-anterior, e mostra a bala collocada á esquerda da columna vertebral. 

d) descahimento da espadua, que se projecta um tanto para a frente, reduzindo a distancia arromio-esternal;

e) desvio externo da borda espinhal do omoplata; menor abducção do braço;

f) cansaço precoce nos esforcos com o membro śuperior;

g) dôres na espadua e região clavicular".

Apresentava o nosso doente os signaes descriptos em b, c $\boldsymbol{\theta}$ parcialmente em d, como attestam as nossas medidas e photographiag apanhadas, embora na n. 4 exista uma inclinação voluntaria ,nitida, da extremidade cephalica. para o lado esquerdo. E' patente o desvio para fóra soffrido peio omoplata esquerdo, que assim causa um augmento ,nesse lado, da distancia existente entre a borda espinhal $\epsilon$ a linha espondiléa. Os signaes cutalogados em e e f foram prejudicados em sua pesquisa, $\in \mathrm{m}$ virtude da hemiplegia heterolateral, que assim roubou o contrôle indispensavel para sua fiel avaliação.

III) - Paralysia do XII: - Peia lesão do XII par fala a glossoplegia presente. Considerada no interior da cavidade buccal, mostra-se a lingua desviada para a direita, com descoramento e atrophia do dimidio esquerdo. O lesvio quando estudado após projecção para fora, inverte-se, pois neste momento, ensina a physiologia, entram em actividade as fibras medias do genı-gosso do lado illeso, as quaes ,em parte - e dahi a explicação do desvio para o lado paralysado - se cruzam na linha mediana, abaixo do septo lingual, com as heterolateraes.

Pela pallidez do lado doente responde, ao nosso ver, o compromettimento das fibras para-sympathicas, do systema vago, que tem a sua origem em um nucleo myelencephalico e que fazem parte integrante do tronco do nypoglosso. Destruidas essas fibras, entram em estado de hypertonia as do systema thoraco-lombar, de acção opposta, vaso-constrictora sobre a lingua. Nem todos acceitam esta concepção anatomica e płysiologica de Guillaume. Testut, (1) por expmplo, é de opinião c,ue as fihras vaso-dilatadoras são levadas pẹo lingual e as de asçĩo antagonica pelo hypoglosso. Destôa da observação corriçueira dá clinica este modo de pensar.

IV) - Irritação do VII: - Tem J. O. um desvio da comissura labial esquerda. Duas hypothece.3 podem ser aventadas para sua explicação: a) paralysia do facial inferior direito; b) contractura do facial esquerdo. Seja, embora a primeira a que naturalmente so responsabilisa por aquella asymetria da face, opinámos, desde o inicin, pela segunda, consideranto a sua difficil conciliação com a paralysia dos nervos bulbares, verificadas no lado opposto.

O exame electrico, mostrando integridade do facial direito, veio fortalecer nossa opinião. Fica, deste modo, explicada o desvio pela irritação das fibras do tacial infericr esquerdo, afferentes ao risorius de Santorini, buccinador e metade inferior do orbicular dos labios.

V) - Irritação do V: - Ha hyperesthesia da hemiface esquerda. () tri-facial parece compromettido. A irritação das fibras que destribuem á face, pelo projectil, explicaria essa perturbação da sensibilidade superficial.

(1) TESTUT. - Traité id'Anatomit, V. III. 


\section{DIAGNOSTICO}

E' portador J. O. de uma hemiplegia syndromo alterno de Jackson complicado, incompleta. O diagnostico differencial com as differentes paralysias alternas descriptas, não offerece difficuldade. 0 seu cunjuncto clinico não póde ser identificado ás alternativas possiveis e verificadas de uma alteração na esphera sensitivo-motora com um dos syndromos seguintes, conforme muito didacticamente resume 0 Prof. Aloysio de Castro:

a) Syndromo de Avellis: - Hemiplegia palato-laryngéa (lesão do ramo interno do XI)

b) Syndromo de Schn:idt: - Hemiplegia palato-escapulo-laryngéa (lesão total do XI)

c) Syndromo de Jackson: - Hemiplegia glosso-palato-escapulolaryngéa ou glosso-palato-laryngéa (lesão total ou parcial do XI e do XII.

d) Syndromo de Tapia: - Hentiplegia glosso-laryngéa ou glossoescapulo-laryngéa (lesão incompleta do XI e do XII)

e) Syndromo de Siccard a Collet: - Hemiplegia glosso-laryngoescapulo-pharyngéa com ageusia e tachycardia (lesão dos 4 ultimos nervos craneanos)

f) Syndromo de Vernet: - on do orificio lacero-posterior. Hemiplegia palato-escapulo-pharyngo-laryngéa com hemi-anesthesia pharyngo-laryngśa, ageusia e tachycardia (lesão do IX, X, XI, completa ou ñ̃o)

g) Syndromo de Villaret: - ou do espaço retro-parotidiano posterior. Hemiplegia glosso-palato-laryngéa, com ageusia e syndromo de Claude Bernard-Horner (lesão do IX, X. XI incompleto, XII e sympathico cervical)

Diagnostico topographico.

A therapeutica a seguir e o prognostico a formular dependem. sem duvida alguma, do diagiostico topographico. Onde foi o systema nervoso attingido fara que surgisse o quadro morbido. bizarro e interessante, descripto? Este é o ponto de mais difficil solucâo.

A radiographia n. 1 mostra a bala collocada lateralmente á coIumna cervical, á altura da 2." vertebra. A n. 2 a sua situação á esguerda. Ella penetrancio pela face, atravessando a cavidade buccal e attingindo a região cervical do mesmo lado, o fez sem penetrar n: cavidade craneana. Esta observação accrescida da ausencia de phenomenos graves bulbares, como muito bem fez ver o Prof. Ovidio Pires de Campos, permitte o afastamento de uma offensa directa do bulbo, que, verificada, na sua parte lateral, explicaria sufficientemente as alterações presentes. De facto, o projectil então attingiria as fibras pyramidaes, antes do seu entrecruzamento - dahi a remiplegia heterolateral, - as da fita de Reil, ou do feixe de Gowers - - donde a hemi-hypoeschesi $i$ e. finalmente os filletes do vago, espinhal e hypoglosso. A hyperestbesia da face e desvio da bocca para o lado esquerdos seriam esplicados, a primeira pela dos filletes de trigemeo, ou da sua columna sensitiva bulbar e o segundo pelo das fibras do facial inferior.

Visto não ter a bala penetrado na cavidade craneana é mais verosimil terem sido as lesões causadas pelo compromettimento dos 
c.unductos nervosos fóra della. A lesão do X. XI e XII pares comrehende-se bem, consilleradas as suas relações, quando atravessam us buracos despedaçado posterior e condyliano anterior. Si é facil explicar a paralysia dos nervos, outro tanto não succede com o apparecimento das perturbaçùes sensitivo-motoras.

Achamos difficil que a hemiplegia direita seja o effeito de uma lesão homolateral da meciulla, pois semelhante facto verificado traria uma hemi-anesthesia hetero-lateral,reproduziria o syndromo de BrownSequard. Pensamos, antes, em uma hemorrhagia, não rara nos casos de traumatismo da região oceipital, comprimindo a parte anterolateral esquerda do bulbo e occasionando as perturbações sensitivomotoras estudadas. Fale em pról desta hypothese a melhoria accentuada surgida com a evolução da molestia.

Considerando a hemiplegia velo-palatina e a paresia do esternoclcido e trapezio, innervados, respectivamente, por filletes que partem da porção supero-externo do glangio plexiforme e do ramo externo do XI par, resalta a necessidade de uma lesão alta dos troncos nervosos.

O trismo notado em J. O., muito pronunciado no inicio, bem meluorado mais tarde, parece correr por conta do edema e outras lesões da cavidade buccal.

Cortejo clinico semelhante, apenas em parte, ao que descrevemos pode ser encontrado nos iasos de hemorrhagia da arteria cerebellosa posterior e inferior, ramc que a rertebral emitte um pouco acima dn espinhal. Esse vaso tem a parte lateral do bulbo como zona de destribuição. Sua ruptura, como diz Van Gehuchten (1) é mais commum nos velhos, e dá lugar ao seguinte: a) pert. sensitivas no territorio do $\mathrm{V}$ par (lesão da raiz descendente bulbar) e no lado opposto do corpo com dissociação seringomyelica (lesão do feixe de (rowers); b) pert. da motilidade, homolateral, comprehendenđo a p.resia ou paralysia dos musculos da pharynge e da larynge (lesão do nucleo ambiguo, da fáce (lesão do facial) da lingua (nucleo do XII), nystagmus e por vezes paralysia do sympathico cervical.

(1) Les maladies nerveuses. - 1920.

O TRATAMENTO INGLEZ ANTI-RHEUMATICO ALARCON DE MARBELLA faz desapparecer em poucas horas toda classe de dôres rheumaticas. Informações gratis, sobre esse methodo de tratamento durante poucos dias, á rua de São João, 26. 